\title{
ОСОБЕННОСТИ И ПРОБЛЕМЫ СОЦИАЛЬНО-ЭКОНОМИЧЕСКОГО РАЗВИТИЯ АРКТИЧЕСКОЙ ЗОНЫ РОССИЙСКОЙ ФЕДЕРАЦИИ *
}

\author{
(c) 2020 Петров А.М. \\ доктор экономических наук, профессор Департамента учета, анализа и аудита \\ Финансовый университет при Правительстве Российской Федерации, Россия, Москва \\ E-mail: palmi@inbox.ru \\ (C) 2020 Гизатуллина О.М. \\ кандидат экономических наук, доцент Департамента учета, анализа и аудита \\ Финансовый университет при Правительстве Российской Федерации, Россия, Москва \\ E-mail: OMGizatullina@fa.ru \\ (C) 2020 Мустафаева C.P. \\ аспирант Департамента учета, анализа и аудита \\ Финансовый университет при Правительстве Российской Федерации, Россия, Москва \\ E-mail: SRMustafaeva@fa.ru
}

Арктическая зона Российской Федерации обладает разнообразными и уникальными ресурсами, которые могут привести Россию на новый уровень экономического развития в период правильной и эффективной государственной политики. Эти процессы, в свою очередь, приведут к социальноэкономическому и инновационному развитию не только арктический регион, но и всю страну в целом.

Ключевые слова: Арктическая зона Российской Федерации, социально- экономическое развитие, зоны поддержки.

Конкурентоспособность российской экономики на мировом рынке будет расти. Россия сможет укрепить свои позиции с ее уникальными и богатыми минеральными и интеллектуальными ресурсами. Кроме того, АЗ является очень специфической мишенью для стратегического анализа, исследования и контроля ее развития. Специфика российской АЗ заключается в нескольких особенностях:

- большой размер территории, которая должна контролироваться при ее приблизительном условном и неравномерном зонировании: развитие регионов в рамках макрорегиона;

- концентрация и богатство природных ресурсов и сырья в этой зоне;

- специальная климатическая карта и зона ограничения холода и вечной мерзлоты;

- дефицит и незавершенность, а также рассредоточение и редкость всех видов инфраструктуры на территории, концентрация в основных городах и вахтовых поселках, концентрация на Северном морском пути;

- относительное развитие западных райо- нов и социально-экономическая отсталость восточных районов Арктики;

- стратегии выживания и борьбы за ресурсы доминируют в политике регионов;

- фактическое отсутствие представительства интересов Арктической зоны как единого субъекта развития.

Арктическая зона России представляет собой искусственное территориальное образование, его можно рассматривать как пространственный порог социально-экономического развития. Объект, который формируется по двум критериям: во-первых, береговое положение (море Северного Ледовитого океана), а во-вторых, расположение территории к северу от полярного круга. Однако этого недостаточно для правильной идентификации развития районов АЗ Российской Федерации, отсюда должен быть рассмотрен более широкий круг конкретных критериев. Кроме того, серьезной задачей является разработка инновационных моделей управления развитием регионов.

Достижение цели превращения россий-

\footnotetext{
* Статья подготовлена по результатам исследований, выполненных за счет бюджетных средств по государственному заданию Финуниверситету
} 
ской АЗ в точку роста экономики всей России и ее переход на новый уровень развития возможен благодаря созданию Арктической зоны инновационно-промышленных кластеров. Это даст новые знания, инновации и материал для развития экономики. В арктической зоне есть несколько регионов (Мурманская и Архангельская области), на территории которых существуют сценарии промышленного и постиндустриального развития. Сначала необходимо создать и разработать кластеры, для формирования которых имеются предпосылки в регионах АЗ: разработка системы автомобильных дорог, железных дорог, сети региональных аэропортов. Эти проекты способствуют развитию необходимой инфраструктуры для территории, на которой базируется модель постиндустриального инновационного развития [1].

Эта модель управления должна строиться не только на обычных прогнозных показателях, которые основаны на прошлых и представить опыт, но и более глубоком анализе тенденций, с одной стороны, потенциал регионов и страны в целом, с другой стороны, и по привлечению и созданию широкой сети экспертов, с участием третьей стороны. С этой целью построение модели экономического развития российской АЗ должно учитывать полноту видения стратегии разработки объекта на основе мониторинга и специально организованного наблюдения [2].
Существует разобщенность и отсутствие системы исследований и изучения отдельных районов развития Арктики, что связано с отсутствием специально ориентированной программы по интеграция исследовательской деятельности в Арктике и сложность исследования. Кроме того, ряд основных проблем, отраженных в таблице 1 , не решены.

Ключевые нерешенные вопросы:

- в области наблюдения - есть сложность объекта исследования, проблема идентификации арктических зон регионов, определение и установление четких критериев классификации территории российской АЗ, проблема достоверности информации на уровне муниципалитетов, отсутствие консолидированной информации для создания стратегии развития российской арктической зоны;

- в отношении анализа - отсутствует единый центр сбора, обработки и проектирование модели развития, имеется необходимость оптимального выбора нескольких конкурирующих сценариев развития на территории регионов Российской Арктики и с государственной точки зрения в целом.

Четкое определение регионов, входящих в A3 России, необходимо для решения проблем стратегии ее развития. Существует несколько довольно нечетких критериев классификации территорий в направлении арктической зоны.

Таблица 1. Проблемы мониторинга экономических процессов в российских арктических регионах и возможные пути их решения

\begin{tabular}{|c|c|c|c|}
\hline № пп & Инструменты & Проблемы & Возможные решения \\
\hline 1 & $\begin{array}{l}\text { Наблюдения: } \\
- \text { бухгалтерский } \\
\text { учет; } \\
\text { - сложность } \\
\text { объекта }\end{array}$ & $\begin{array}{l}\text { Проблема достоверной и не- } \\
\text { достоверной информации на } \\
\text { уровне муниципалитетов. } \\
\text { Отсутствие консолидирован- } \\
\text { ной информации, единой } \\
\text { стратегии и модели развития } \\
\text { российской Арктики. }\end{array}$ & $\begin{array}{l}\text { Требуется мониторинг развития территорий } \\
\text { Арктической зоны. Валовой региональный про- } \\
\text { дукт (ВРП) и Муниципальный валовой продукт } \\
\text { (ГВП) могут быть использованы для комплексной } \\
\text { оценки уровня развития субъектов Российской } \\
\text { Федерации или муниципалитетов, которые обра- } \\
\text { зуют зоны АЗ, соответственно. } \\
\text { Строительство российской арктической зоны как } \\
\text { объект разработки стратегии и создания сцена- } \\
\text { риев. }\end{array}$ \\
\hline 2 & $\begin{array}{l}\text { Типологическая } \\
\text { группировка }\end{array}$ & $\begin{array}{l}\text { Определение российской } \\
\text { арктической зоны, опреде- } \\
\text { ление и установление четких } \\
\text { критериев. }\end{array}$ & $\begin{array}{l}\text { Определение и установление четких критериев } \\
\text { идентификации территорий, образующих аркти- } \\
\text { ческую зону. }\end{array}$ \\
\hline 3 & Анализ & $\begin{array}{l}\text { Отсутствие единого центра } \\
\text { сбора, обработки инфор- } \\
\text { мации и проектирования } \\
\text { моделей развития. }\end{array}$ & $\begin{array}{l}\text { Проведение комплексного статистическо- } \\
\text { го исследования, которое предполагает экс- } \\
\text { траполяцию и моделирование социально- } \\
\text { экономического развития. }\end{array}$ \\
\hline 4 & Моделирование & $\begin{array}{l}\text { Несколько возможных кон- } \\
\text { курирующих сценариев. }\end{array}$ & $\begin{array}{l}\text { Построение будущего имиджа территории на } \\
\text { основе когнитивного моделирования и предви- } \\
\text { дение. }\end{array}$ \\
\hline
\end{tabular}


Однако, требуется построение модели социально-экономической системы АЗ России.

Построение такой сложной модели социально-экономической системы АЗ возможно на основе нестабильных агрегатов концепции исследования. Арктическая зона России как социально-экономическая система представляет собой искусственную территориальную единицу, ее можно рассматривать как пространственный социально-экономический объект (совокупность регионов). Агрегаты - это статистические критерии, введенные искусственным путем.

Юридически определенная совокупность регионов АЗ России формируется по двум критериям: местонахождение субъектов в пределах Полярного круга и выход к Северному Ледовитому океану, связь с акваторией Северного морского пути.

Использование границ полярного круга в качестве критерия для определения границ Арктики принято в науке. По этому критерию все территории, которые находятся к северу от $66^{\circ} 33^{\prime}$ северной широты, а также Административнотерриториальные единицы, через которые проходит Северный полярный круг, являются арктическими регионами. Полагаем, что этих условий недостаточно для правильной идентификации регионов российской арктической зоны, необходимо использовать более широкий спектр конкретных критериев и научную обоснованность такой идентификации.

В качестве рабочей гипотезы необходимо рассматривать Арктический регион как интегрированный регион с общими условиями, особенностями, проблемами, факторами и источниками развития. Кроме того, следует отказаться от территориального деления регионов России в пределах арктической зоны. Для того, чтобы определить регионы в Арктической зоне предлагается использовать несколько дополнительных критериев: природно-климатические критерии, характеризующие уровень жизненного дискомфорта, а также социально-экономические критерии, характеризующие уровень дискомфорта населения с точки зрения социальноэкономических условий.

Для определения порогов и дифференциа- ции совокупного порога, то есть идентификации регионов как части Арктической зоны Российской Федерации мы предлагаем использовать инструменты пробит-регрессии. Инструменты пробит-регрессии позволят построить пробитную модель.

Пробитная модель может быть использована для классификации объектов, которые характеризуются двумя типами признаков:

- зависимая переменная или эндогенная (переменная-результат), выражаемая в номинальной или порядковой шкале существует в альтернативной форме. Другими словами, есть только два варианта, два типа явлений, таких как «да» или «нет»;

- независимые переменные или экзогенные - переменные, характеризуют явления или процессы и выражаются в интервале шкалы.

Пробитные модели являются моделями бинарного выбора, они широко используются в различных экономических и социальных исследованиях. Различные критерии для классификации районов (муниципалитетов) к арктической зоне могут использоваться в качестве входных данных для расчетов пробитовой регрессии. Помимо географического положения, они могут быть:

- продолжительность дня (часы);

- продолжительность зимнего периода (дни);

- распространением вечной мерзлоты;

- среднегодовая температура.

Зависимая переменная представлена в виде вектора столбца, состоящего из единиц и нулей (формула 1).

Оценка параметров пробит-регрессионных уравнений с помощью квазиньютоновских методов. На выходе мы имеем вероятность отнесения регионов РФ к арктической зоне.

Результатом является список муниципалитетов, которые явно относятся к арктической зоне. Вышеуказанные показатели позволяют классифицировать муниципалитеты и сложные метарегионы. В будущем правительствам предлагается рассмотреть эту типологию, когда субъекты арктической зоны будут выделены.

Предметы связаны с разобщенностью субъектов и различными уровнями управления

$$
f(x)=\left\{\begin{array}{l}
0, \text { регион не относится к российской арктической зоне } \\
1, \text { регион относится к российской арктической зоне }
\end{array}\right.
$$


(от муниципальных районов до субъектов Российской Федерации) и, соответственно, различные степени агрегирования информации. Это должно быть решено путем создания единого центра по сбору, обработке информации и проектированию модели развития. Программа статистического мониторинга субъектов арктической зоны России должна включить единый для всех регионов АЗ РФ список статистических показателей, независимо от уровня управления (включая показатели результатов хозяйственной деятельности: по муниципальным районам - Валовой муниципальный товар, а для субъектов федерации - валовой региональный продукт).

Проблемы оценки современного состояния и перспектив экономического развития регионов Арктики.

Инструменты пробитовой регрессии предлагается применять для идентификации регионов как части арктической зоны. Использование валового муниципального продукта позволяет сделать сравнительную оценку уровня отдельных регионов освоения Арктики. Данная методология позволит проводить комплексное статистическое исследование с целью прогнозирования и моделирования социально-экономического развития Арктической зоны Российской Федерации и сравнение их с ожидаемыми результатами.

Основным инструментом реализации приоритетных направлений роста арктической зоны Российской Федерации являются, в основном, Государственные программы Российской Федерации и субъектов Российской Федерации, закрепленные за Российской Арктикой, прежде всего, в повышении качества жизни населения, население арктических территорий и развитие транспортной и энергетической инфраструктуры.

В целях повышения уровня жизни, прежде всего коренного населения, последовательно реализуются мероприятия по социальной инфраструктуре, реконструкции жилищного фонда и жилищно-коммунального хозяйства; принимаются меры по повышению качества оказания медицинской помощи, особенно в отдаленных и труднодоступных районах. На данный момент население арктической зоны обеспечено современными информационными и телекоммуникационными услугами.

Проводится комплексное научное исследо- вание арктических морей, континентального шельфа и материка арктической зоны Российской Федерации, направленное, прежде всего, на расширение базы научных знаний о регионе, а также на развитие ресурсной базы. Масштабный комплекс научных исследований направлен на разработку специальных материалов и технологий, адаптированных к арктическим условиям, в том числе автономных источников энергоснабжения с использованием возобновляемых источников энергии.

Комплексы горнодобывающей и рыбной промышленности неуклонно развиваются. Углеводородные ресурсы добываются активными темпами, что дает мощный импульс совершенствованию транспорта, прежде всего морской инфраструктуры. Активно проводятся мероприятия, связанные с предотвращением и минимизацией загрязнения окружающей среды, устранением ущерба окружающей среде, обнаружением опасных природных явлений, особенно вблизи стратегических целей. Активно принимаются меры по предотвращению и минимизации загрязнения окружающей среды, устранению ущерба окружающей среде, выявлению опасных природных явлений, особенно вблизи стратегических объектов гражданской и военной инфраструктуры.

Таким образом, за последнее десятилетие (после периода начала 1990-х и до середины 2000-х годов, когда у России не было четкого стратегического видения развития этих территорий), Россия достигла значительных успехов в регионе: новые крупные масштабные проекты по добыче полезных ископаемых, строительству новых и модернизации существующих морских портов, новых ледоколов, региональные проекты, направленные на повышение социальноэкономического развития и качества жизни.

В то же время, на фоне меняющейся природы международных отношений в последние годы, активных инициатив неарктических государств в развитии экономической деятельности в регионе, формировании нового подхода к управлению и новых инструментов экономической политики в Арктике в условиях ограниченных финансовых ресурсов становится актуальной для России.

В последние годы программы социальноэкономического развития Арктики реализуются самостоятельно. Иногда мы можем наблюдать дублирование деятельности. Это свидетельству- 
ет о неэффективности расходования бюджетных средств. Степень освоения и освоения арктических территорий зависит не только и не столько от объема финансирования, сколько от согласованности, последовательности и взаимосвязанности деятельности.

Однако текущей деятельностью мы не можем обеспечить ассоциативность реализации документов стратегического планирования для социально-экономического развития российской арктической зоны. В то же время эта область является макрорегионом, где вопросы социально-экономического развития и защиты национальной безопасности максимально взаимосвязаны. Это касается как инфраструктуры, так и технологий, где Россия обладает и занимает лидирующие позиции в мире, благодаря чему Российская Федерация может уверенно наращивать свое интеллектуальное присутствие в Арктике.

Необходимость преодоления высоких затрат и специфических факторов северного признания обуславливает консолидацию взаимосвязанных мер экономического регулирования и стимулирования на уровне планирования и программирования. При этом учитываются особенности условий экономики, стратегические национальные приоритеты и приоритеты социальноэкономической политики, а также ограничения, налагаемые климатическими, социальными и социокультурными, экологическими, технологическими, международно-правовыми и другими основаниями.

Все вышеизложенное свидетельствует о том, что на современном этапе мы сталкиваемся с необходимостью перехода к новой модели пространственного социально-экономического развития и управления экономикой, создающей структуру региональных (республиканских, областных, областных, районных) и территориальных (городских, районных) центров концентрации экономического роста, формирующих и передающих инновационные импульсы экономического развития соседним территориальным образованиям; модель способную управлять вышеизложенными процессами, используя рыночные институты и механизмы, выводя окраины и территории на путь ускоренного развития.

Разрозненная инфраструктура в Арктике обуславливает особое значение в части поддержания, развития и модернизации уже созданных центров экономической деятельности, создания новых, усиления их интеграции. Региональный подход к арктическому пространству не нов, и в свое время он добился значительных успехов. В нынешней реальности политики санкций и бюджетных ограничений этот подход может быть реализован посредством крупных инвестиций государственных, региональных и частных проектов, основанных на принципах государственно-частного партнерства.

Далее необходимы разработка и механизмы реализации инвестиционных проектов, в том числе проектов, основанных на принципах государственно-частного партнерства. Такой подход позволит не только обеспечить целостность на этапе постановки целей, но и снизить затраты.

Территориальные зоны планируется создать в каждом субъекте российской Арктики, но реализация этих проектов должна дать толчок развитию всей арктической зоны России, а не только ее отдельных участников. Прежде всего, проекты федерального значения должны быть направлены на развитие арктического макрорегиона, а не только на решение конкретных отраслевых задач.

Формирование зон поддержки развития Арктики предусматривают подход к развитию территории как целостного проекта, основанного на принципе обеспечения ассоциативности всех «отраслевых» видов деятельности на этапах планирования, постановки целей, финансирования и реализации, которые в свою очередь, позволят существенно сократить различные затраты. Такие зоны также будут влиять на развитие внутренних районов, чья экономическая деятельность напрямую зависит от состояния российской Арктики и ее инфраструктуры. Ориентация зон поддержки на морские порты Северного морского пути оживит деятельность судостроительных и судоремонтных предприятий как в Арктической зоне, так и в других регионах Российской Федерации.

Вышеперечисленные комплексные проекты обеспечат ассоциативность мероприятий, связанных с созданием арктической транспортной системы, ростом энергетической инфраструктуры, промышленных объектов, синхронным использованием существующих инструментов территориального развития и механизмов поддержки реализации инвестиционных проектов.

В целом, под зоной поддержки можно по- 
нимать часть территории субъекта Российской Федерации, расположенной в арктической зоне России, где реализуется один или несколько инвестиционных проектов, требующих создания единой глобальной энергетики и транспорта. В свою очередь инфраструктура и привлечение трудовых ресурсов могут рассматриваться как единый комплекс для подавления непродуктивной конкуренции. В то же время недостаточный уровень развития инфраструктуры затрудняет привлечение инвестиций для промышленного освоения арктических территорий, а также значительно снижает качество жизни. В связи с этим реализация наиболее значимых промышленных и социальных проектов изначально ограничивается существующими отказами инфраструктуры, включая развитие транспорта, энергетики и связи. Таким образом, на данном этапе модель государственного управления будет ориентирована на формирование инфраструктуры и энергетических рамок, которые должны оказывать мультипликативный эффект и придавать импульс развитию всего региона.

Зоны поддержки - новый инструмент государственного управления в Арктике.

Идея формирования зон поддержки развития, предложенная в качестве основного инструмента реализации государственной политики в российской Арктике, направлена на создание каркаса центров экономического роста, обладающих мультипликативным эффектом. Для современной России этот подход является новым, поскольку он подразумевает развитие не отдельных секторов, а арктических территорий, накапливая усилия и ресурсы государства не на отдельных изолированных проектах, а только на тех, которые будут оказывать комплексное воздействие на развитие территорий (опорных зон). Другими словами, государство создаст условия для точек роста арктической экономики. В таблице 2 приведем основные принципы формирования опорных зон в Арктике.

Таблица 2. Основные принципы формирования опорных зон в Арктике

\begin{tabular}{|c|c|c|}
\hline № пп & Принципы & Описание мероприятий \\
\hline 1 & Согласованность & $\begin{array}{l}\text { Проекты, которые формируют зону поддержки, должны быть скоорди- } \\
\text { нированы, взаимосвязаны на этапах постановки целей, планирования } \\
\text { и реализации с учетом социально-экономического развития региона и } \\
\text { государства в целом, а также национальной безопасности, которая значи- } \\
\text { тельно снизит затраты на их реализацию. }\end{array}$ \\
\hline 2 & Мультипликативность & $\begin{array}{l}\text { Реализация проектов зоны поддержки должна дать мультипликативный } \\
\text { эффект и способствовать повышению эффективности и диверсификации } \\
\text { экономики арктической зоны, стимулировать развитие близлежащих тер- } \\
\text { риторий и шельфовых производств. }\end{array}$ \\
\hline 3 & Социальный эффект & $\begin{array}{l}\text { Функционирование зон поддержки должно способствовать улучшению ка- } \\
\text { чества жизни в регионе, нивелированию дисбалансов в территориальной } \\
\text { структуре региона, прежде всего, преодолению разрыва между расположе- } \\
\text { нием производства и населением, созданию новых рабочих мест. }\end{array}$ \\
\hline 4 & $\begin{array}{l}\text { Обеспечение экологиче- } \\
\text { ской безопасности }\end{array}$ & $\begin{array}{l}\text { Арктическая экосистема уникальна, имеет планетарное значение. Её } \\
\text { сохранение, снижение до минимально допустимого значения выбросов } \\
\text { вредных и загрязняющих веществ и, если возможно, их устранение, разра- } \\
\text { ботка и внедрение природоохранных технологий являются принципами, } \\
\text { которые следует учитывать при разработке любого проекта в Арктике. } \\
\text { Такой подход позволит сохранить как экосистему этого региона, так и } \\
\text { самобытность и культуру коренных народов российского Севера, органи- } \\
\text { чески связанных с арктической природой. }\end{array}$ \\
\hline 5 & $\begin{array}{l}\text { Обеспечение националь- } \\
\text { ной безопасности }\end{array}$ & $\begin{array}{l}\text { Обеспечение национальной безопасности во всех областях, определенных } \\
\text { в Стратегии национальной безопасности Российской Федерации до } 2020 \\
\text { года, и реализация национальных интересов России в Арктике, опреде- } \\
\text { ленных в «Стратегии развития Арктической зоны Российской Федерации } \\
\text { и обеспечения национальной безопасности». Безопасность на период до } \\
2020 \text { года». Учитывая стратегическую важность этого региона, работа зон } \\
\text { поддержки должна быть направлена на решение региональных проблем } \\
\text { и быть напрямую связана с обеспечением национальной безопасности, } \\
\text { прежде всего в сфере национальной обороны, контроля на границах, безо- } \\
\text { пасности и охраны в случае чрезвычайных ситуаций, повышения качества } \\
\text { жизни населения, включая продовольственную безопасность и обеспече- } \\
\text { ние экономического роста. }\end{array}$ \\
\hline
\end{tabular}


Поскольку целью поддержки зон развития в Арктике является интенсификация и диверсификация региональной экономики, целесообразно создать зоны поддержки вокруг «якорного» проекта, который мог бы служить связующим звеном в реализации других проектов. Очевидно, что эти проекты должны иметь приоритет и должны обеспечиваться, когда это необходимо, координацией на уровне департаментов, иметь мультипликативный эффект и оказывать значительное влияние на развитие смежных отраслей, инфраструктуры и социальной сферы. Кроме того, такие проекты должны быть конкретными и целевыми, иметь одобренное финансирование, окончательные результаты, основанные на объектах, и четко определенные сроки и этапы реализации.

Исходя из описанных основных тенденций, особенностей и проблем социальноэкономического развития Арктической зоны Российской Федерации, следует выделить следующие приоритеты развития АЗ:

1) Создание, развитие и реконструкция объектов арктической транспортной системы, являющейся национальным арктическим транспортным комплексом, ориентированной на круглогодичную эксплуатацию, включая Северный морской путь и комплекс транспортных средств морского и речного флота, авиационный, трубопроводный, железнодорожный и автомобильный транспорт и соответствующую инфраструктуру, в том числе береговую, обеспечивающую транспортную деятельность в арктической зоне. Ядром этой системы является Северный морской путь, служащий связующим звеном во всей арктической экономике. Кроме того, его бесперебойное функционирование является фактором жизнеобеспечения для большинства прибрежных и континентальных регионов российской Арктики и Крайнего Севера. Функционирование Северного морского пути невозможно без развитых логистических центров и сети портовых сооружений, наличия подъездных путей и другой транспортной инфраструктуры, системы обеспечения безопасности мореплавания и спасения на море. Таким образом, зоны поддержки развития Арктики должны формироваться на основе решения этих проблем.

2) Развитие объектов горно-обогатительной промышленности. Арктическая зона об- ладает самыми богатыми запасами полезных ископаемых, которые имеют не только общероссийское, но и мировое значение. Когда Арктическая зона Российской Федерации рассматривается как «стратегическая ресурсная база России, обеспечивающая решение задач социальноэкономического развития страны», приоритет следует отдавать проектам, направленным на разработку месторождений углеводородов, горнорудного комплекса, модернизацию рыбной и рыбоперерабатывающей промышленности, развития аквакультуры и других отраслей, способствующих обеспечению импортозамещения и национальной безопасности страны.

3) Развитие и создание объектов энергетической инфраструктуры. Почти все арктические регионы России испытывают дефицит энергии, что препятствует их развитию и росту. Проекты, направленные на снижение таких негативных процессов, могут послужить стимулирующим фактором для активизации экономической деятельности в регионе, создания энергоемких производств и будут способствовать повышению уровня жизни.

4) Реконструкция и развитие объектов коммунального хозяйства, социальной сферы, здравоохранения. Для преодоления негативной тенденции миграции трудоспособного населения из российских арктических регионов необходимы проекты, направленные на повышение уровня жизни, а также содействие формированию высококвалифицированных кадров для нужд региональной экономики, рассматриваемые как приоритет в формировании зон поддержки. Кроме того, своевременная высокотехнологичная медицинская помощь населению чрезвычайно важна в условиях удаленности территорий, неблагоприятной климатической и сложной техногенной ситуации в арктических регионах.

5) Развитие объектов, имеющих оборонное значение. Арктический регион имеет большое стратегическое значение с точки зрения защиты национальной безопасности в военной сфере. Географическое положение этого региона позволяет силам и средствам российского флота беспрепятственно получать доступ к Мировому океану, развертывать противоракетную оборону и т.д. 


\section{Библиографический список}

1. Vladimir Glinskiya, Lyudmila Sergaa, Kirill Zaykova Identification Method of the Russian Federation Arctic Zone Regions Statistical Aggregate as the Object of Strategy Development and a Source of Sustainable Growth, Procedia Manufacturing, Volume 8, 2017, Pages 308-314

2. Меламед И.И., АвдеевМ.А., Павленко В.И., Куценко С.Ю. Российская арктическая зона в социальноэкономическом развитии. Власть, 2015, № 1, с. 5-11.

3. Никифорова Е.В., Гизатуллина О. М., Шнайдер О.В. Анализ и оценка структуры экономики и транспортного обеспечения Арктической зоны РФ. Вестник СамГУПС, 2020, № 1 (47). С. 18-24

4. Gizatullina, O.M. FEATURES OF ACCOUNTING COSTS IN OIL COMPANIES IN THE ARCTIC= Особенности учета затрат в организациях нефтегазовой отрасли Арктической зоны / O. M. Gizatullina, T. M. Tarasova// European Proceedings of Social and Behavioural Sciences EpSBS Pages 1-1004 (01.04.2020) e-ISSN: 2357-1330 Conference: 18th International Scientific Conference "Problems of Enterprise Development: Theory and Practice" (PEDTR 2019)

5. Шнайдер О.В., Петров А.М., Боровицкая М.В. Система оценки рисков, обусловленных влиянием суровых климатических условий на экономику Арктической зоны Российской Федерации // Экономические науки. 2019. № 171. С. $134-138$.

6. Чижков Ю. В. Северный морской путь в структуре Арктической транспортной системы // Транспорт Рос. Федерации. - 2017. - № 1 (68).- С. 27-32.

7. Бабаев Ю.А., Друцкая М. В., Кеворкова Ж.А., Листопад Е.Е., Петров А. М. Бухгалтерский учет, анализ и аудит внешнеэкономической деятельности / учебник для студентов обучающихся по специальности 080109 «Бухгалтерский учет, анализ и аудит» / под редакцией Ю.А. Бабаева. Москва, 2010.

8. Петров А.М., Мельникова Л. А. Теоретические аспекты учета калькулирования себестоимости продукции / Экономические науки. 2013. № 102. С. 145-148.

9. Kevorkova Z.A., Petrov A. M., Savina N.V. Towards Liabilities Of Corporate Systems / International Journal of Civil Engineering and Technology. 2019. T. 10. № 2. C. 1582-1593.

10. Lymar M.P., Kevorkova Z. A., Petrov A.M. The Convergence Of National And International Accounting Standards: Chinese Experience / International Journal of Civil Engineering and Technology. 2018. T. 9. № 13. C. 82-94.

11. Петров А.М., Коняхин А. Н. Учетная политика при подготовке первой отчетности согласно МСФО / Международный бухгалтерский учет. 2013. № 11 (257). С. 2-15.

12. Petrov A.M., Sembieva L.M. ORGANIZATIONAL AND METHODICAL MECHANISM OF INTERNAL AUDIT OF SETTLEMENTS IN CORPORATE SYSTEMS / Bulletin of the National Academy of Sciences of the Republic of Kazakhstan, Volume 2, Number 384 (2020), 119-127, 2020 